\title{
Field Modelling of Large Scale Compartment Jet Fires by Constrained Equilibrium Method
}

\author{
L. Y. Huang and J. X. Wen* \\ School of Mechanical, Aeronautical and Production Engineering \\ Kingston University \\ Roehampton Vale, Friars Avenue, London SW15 3DW, UK
}

\begin{abstract}
Predictions are presented from a field model for offshore compartment jet fires. The Constrained equilibrium method has been used to couple the calculation of combustion and radiative heat exchange. Soot formation is modelled by a one-equation approach. Radiation is computed with the Discrete Transfer Radiation Method (DTRM) and a published procedure for calculating the Planck mean emission and absorption coefficients of gas-soot mixtures is used to calculate the radiation properties. Comparisons are made with full-scale jet fire tests in a $135 \mathrm{~m}^{3}$ ventilation-controlled compartment. It is found that the model predicts the correct trend of field variables such as velocity, temperature, $\mathrm{CO}, \mathrm{CO}_{2}$ and $\mathrm{OH}$. Soot predictions also show a reasonable distribution. For the two vertical lines within the compartment and at the vent where temperature measurements are available, the predictions are also in reasonably good agreement with the experimental data.
\end{abstract}

KEY WORDS: compartment fires, constrained equilibrium method, radiation, soot modelling

\section{INTRODUCTION}

Following the Piper Alpha disaster in 1988, there has been growing concern about the potential of fires and explosions to cause major offshore accidents. Increased demands have been placed by HSE (Health and Safety Executive) for detailed quantified risk assessment and this in turn requires that the consequences of various scenarios be accurately predicted. Previous investigations of hazardous conditions associated with compartment fires have included both experimental [1-3] and numerical methods based on zone models [4-6], conventional field models [6-9] and large eddy simulation techniques[10]. It is generally accepted that zone models are only suitable if the room is of a rectangular cuboidal shape and

\footnotetext{
"Author to whom correspondence should be addressed.
} 
is 'domestic-sized' [11]. For large-scale compartment fires, it is far from enough to divide the enclosure into two zones as in traditional zone models. Field models are more viable in such situations as they allow the variation of the field variables across the whole compartment in a discretised manner. In principle, there is no limitation on the size or shape of the compartment, which may be modelled.

In the literature on field modelling of compartment fires, most investigators targeted their research on small rooms and non-sooting fires [7-9]. Adding to the complexity of the buoyancy-driven turbulent flow field, under-ventilated sooting fires are also characterised by the spatially varying absorption coefficients for which the soot is a major contributor. A complete differential field model for the dynamics of the fire phenomenon in a compartment should account for the mutual interactions between the fire physical and chemical effects, namely, fluid mechanics, heat transfer, combustion, material and geometry [12]. This has now become increasingly viable with the recent rapid growth in desk top and super-computing power.

The behaviour of large-scale compartment fires in ventilation-controlled conditions has been little studied and is however an important scenario in hazard consequence analysis, particularly on offshore platforms. There are major differences between laboratory and onshore cellulosic fires, and fires that might occur offshore. The differences are in scale, intensity and speed of development. Volumes of offshore modules are typically much larger than those of rooms in domestic dwellings and office blocks. The speed of development for offshore fires is also much faster and the size considerably larger with powers of $3 \mathrm{MW}$ to several gigawatts.

The eddy break-up (EBU) model is the most frequently used combustion model in previously reported compartment fire predictions [7-8]. The recent work by Lewis et al. [8] has also included the use of the laminar flamelet concept with the flamelet library derived from some earlier experimental measurements. The work by Lewis et al. has shown that improved accuracy can be obtained with the use of Discrete Transfer Radiation Method (DTRM).

The authors have previously reported the use of a flamelet model for large-scale offshore compartment fires [13]. But, simplified treatment for radiation calculation was used in the previous study. In the present paper, the constrained equilibrium method [14] is adopted to treat the interaction between combustion and radiative heat loss. This is also coupled with the DTRM [15] for radiation calculation. Hubbard and Tien's [16] Plank mean emission and absorption coefficients concept is used to calculate the radiation properties of the gaseous species and soot. The predicted heat flux on the compartment walls, soot, velocity and temperature, as well as species distributions are presented. Comparisons are also made between the experimental measurements and the model predictions.

\section{NUMERICAL MODELS}

The models presented here have been incorporated within the CFX-FLOW3D software (Version 4.1C) [17]. This is a general-purpose CFD package which solves a set of threedimensional partial differential equations that govern fluid flow, heat transfer and species transport. This set consists in general, of the continuity equation, the momentum equations in three space dimensions, the energy equation, the equation for species concentrations and the 
equations for the turbulence model, in this case the $k-\varepsilon$ model which incorporates buoyancy modifications.

\subsection{Constrained Equilibrium Method}

The flamelet model calculates the temperature, density and species concentrations according to the correlations between these variables and the mixture fraction which can be evaluated from the detailed calculations of the laminar, stagnation point diffusion flame. However, with strong energy losses due to radiation in the sooting diffusion flames, it is difficult to couple the radiation model into it. Kennedy and Kollmann [14] proposed a so-called constrained equilibrium approach to the problem. It consists of taking an equilibrium calculation and imposing a value of enthalpy on the problem. In essence, this can be thought of as cooling the system by some prescribed amount [14]. This is realised by introducing a heat loss factor when performing the equilibrium calculation. As well known, the equilibrium calculation depends only on knowledge of the thermodynamic properties of the species in the system and does not require any information about the reactions, which allow it to relax to equilibrium as long as such reactions exist. Therefore, the equilibrium composition of a reacting mixture is completely independent of any reaction mechanism. In the current study, the equilibrium calculation was performed by CHEMKIN. The energy equation solved in the calculation is as follows:

$$
\frac{\partial}{\partial x_{j}}\left(\rho u_{j} h\right)=\frac{\partial}{\partial x_{j}} \Gamma_{h}\left[\frac{\partial h}{\partial x_{j}}+\sum_{i=1}^{n}\left(\frac{1}{L e_{i}}-1\right) h_{i} \frac{\partial Y_{i}}{\partial x_{j}}\right]-\nabla \cdot q_{r}
$$

Where $\mathrm{h}$ is total enthalpy; $u_{j}$ is velocity component; $\rho$ represents the mixture density; $\Gamma_{h}$ is the transport coefficient; $x_{j}$ is the co-ordinates; $Y_{i}$ describes the mass fraction of species $\mathrm{I} ; L e_{i}$ is the Lewis number of species $\mathrm{i}$ and the $q_{r}$ represents the radiation heat flux which was modelled by Discrete Transfer method and will be described later. After the mean enthalpy distribution is obtained, the heat loss factor can be calculated by:

$$
H_{\text {lows }}=\frac{h-h_{\min }}{h_{\max }-h_{\min }}
$$

Where $\mathrm{h}$ is the enthalpy calculated by eq. (1), $h_{\min }$ and $h_{\max }$ are the enthalpies corresponding to the non-reacting (i.e. isothermal mixing) and fully burning conditions respectively. The values of $h_{\min }$ and $h_{\max }$ can be found by any equilibrium code such as CHEMKIN.

Thus, a two-dimensional table of temperatures, densities and species concentrations as functions of mixture fraction and heat loss factor can be produced. During the computational process, these tables are interpolated to give the values of these field variables at a specified combination of the enthalpy and the mixture fraction. 


\subsection{Radiation Model}

Discrete Transfer method: Previous investigations of Kumar et al. [18] have demonstrated that thermal radiation has significant effect on the fluid dynamics of compartment fires. In the present calculations, the DTRM, a ray-tracing technique, has been used for radiation calculation [15]. Following Luo and Beck [19], the scattering coefficients are considered to be negligible in proportion to the respective absorption coefficients. However, the absorption coefficient $k_{n}$ must be calculated since its value depends on species concentrations, especially the concentration of soot.

The absorption coefficient $k_{a}$ in mixtures involving carbon dioxide, water vapour and carbon soot is very complex. It depends not only on local gas composition, temperature but also on radiation wavelength. In the present calculation, a procedure developed by Hubbard and Tien [16] for calculating the Planck mean emission and absorption coefficients are used. For soot, where the calculation requires specification of the complex index of refraction at all wavelengths, a dispersion theory model is used. For the evaluation of the contribution of $\mathrm{CO}_{2}$ to the Planck mean absorption coefficient, the vibration-rotation bands considered are at $15 \mu$, $10.4 \mu, 9.4 \mu, 4.3 \mu, 2.7 \mu$, and $2.0 \mu$. For $\mathrm{H}_{2} \mathrm{O}$, the $20 \mu$ pure rotation and the $6.3 \mu, 2.7 \mu, 1.9$ $\mu$, and $1.4 \mu$ vibration-rotation bands were included.

\subsection{Soot Formation Model}

The soot model used in the present calculations was proposed by Leung et al. [20]. This model is based on the use of a characteristic pyrolysis product, $\mathrm{C}_{2} \mathrm{H}_{2}$, to link the gas-phase chemistry to the soot formation reactions, with the soot reaction mechanism itself involving nucleation, surface growth, particle coagulation and combustion steps. The model requires the solution of two additional conservation equations for soot mass fraction and soot number density, where the latter is defined here as the total number of primary particles per unit volume of the soot aerosol. In the present calculation, a steady state assumption of the particle number density was made and the particle shape was assumed to be spherical. Therefore, one additional equation is needed only. Details about the implementation of this model can be found in [13].

\subsection{Convective Heat Transfer Modification}

Investigations have shown that the heat transfer rate can be increased by a factor of 3 by using direct impingement, especially with the presence of combustion. As the velocity is zero at the stagnation point, CFD codes generally underpredict the convective heat transfer coefficients in the impinging region. Measurements have shown that convective heat transfer coefficient in a boundary layer is about $35 \mathrm{~W} /\left(\mathrm{m}^{2} \mathrm{~K}\right)$ in the absence of combustion and about $80-120 \mathrm{~W} /\left(\mathrm{m}^{2} \mathrm{~K}\right)$ in the presence of combustion. The present study involves high velocity impinging flame jets. It is, therefore, considered necessary to modify the calculation of the local convective heat transfer coefficients in order to obtain reasonable results. The following modification was made mainly in the impinging region following Gardon and Cobonpue correlation[21]:

$$
N u=1.811 \operatorname{Re}^{0.55} \operatorname{Pr}^{0.33}(H / D)^{-0.55}(R / D)^{-0.45}
$$


Where $\mathrm{Re}$ is the jet Renolds number; $\mathrm{Pr}$ is the Prandtl number; $\mathrm{H}$ is the height between the nozzle and ceiling and $\mathrm{D}$ is the nozzle diameter.

\section{EXPERIMENT CONSIDERED}

For the purpose of model validation, a test case was chosen from the fire testing program which is part of an international joint industry project on "Blast and Fire Engineering for Offshore Topside Structures" [1-2]. As shown in Figure 1, the compartment is $9.8 \mathrm{~m}$ in length, $3.54 \mathrm{~m}$ in width and $3.91 \mathrm{~m}$ in height. The burner is located at the centre of the flow area and the fuel nozzle rises approximately $30 \mathrm{~cm}$ above the floor. A single vent to the room is $2.5 \mathrm{~m}$ long by $2 \mathrm{~m}$ high and is located at the side of the compartment. The fuel, which is propane, was burnt at a rate of $0.33 \mathrm{~kg} / \mathrm{s}$ (about $15 \mathrm{MW}$ ) and initial temperature of $281 \mathrm{~K}$. Thermocouples and gas samplers, as well as radiometers were attached to different parts of the compartment to monitor the fire growth. Bi-directional probes were also attached to the vertical mid-section of the vent.

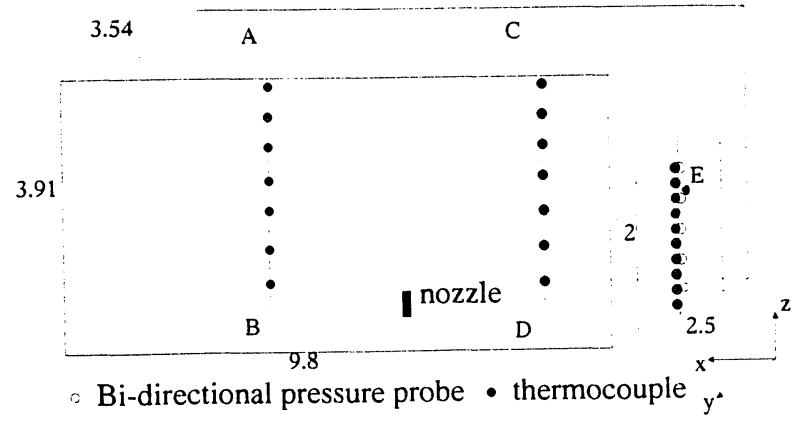

Figure I Schematic of fire compartment and instrumentation. (Reproduced from [1])

\section{GRID DETAILS AND BOUNDARY CONDITIONS}

Because of the symmetry in the tested configuration, only half of the compartment is modelled. While more work is being carried out for grid independent tests, a $94 \times 21 \times 30$ non-uniform grid mesh is used in the current study. The time evolution of the flowfield in the enclosure determines the maximum time step that can provide numerical stability. For the case under consideration a maximum time step of $0.1 \mathrm{~s}$ is chosen to ensure a stable transient solution marching into steady state. At the outlet of the domain the zero-gradient condition is prescribed for all the dependent variables. Constant wall temperature condition is used. The prescribed temperature values are based on the experimental data [1-2].

\section{RESULTS AND DISCUSSION}

The predicted temperature contours at the central section are given in Figure 2. It can be seen 
that there are significant temperature variations within the compartment. For comparison, our earlier predictions, where radiative heat loss was accounted for only by using a constant heat loss factor to modify the instantaneous temperatures given by the flamelet, are also re-plotted in Figure 3. The radiative heat exchange between the compartment wall and the high temperature gaseous products and the cold air were not considered in these earlier calculations. Differences exist between the present and earlier results not just in the maximum values of the predicted temperatures but also in the distribution patterns. This is, to a large extent, attributable to the use of the DTRM sub-model for radiative heat transfer calculation and the strong coupling between radiation and combustion through the use of the constrained equilibrium method in the current prediction. Also in the present study, the mean absorption coefficient concept of Hubbard and Tien [16] is used.

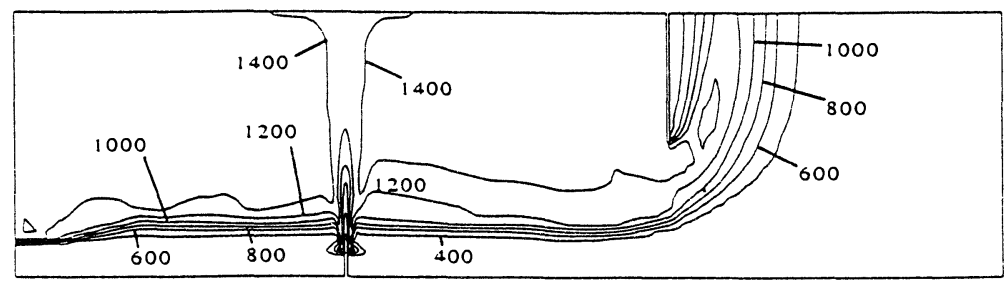

Figure 2 Predicted temperature contours by CE method at central section (K).

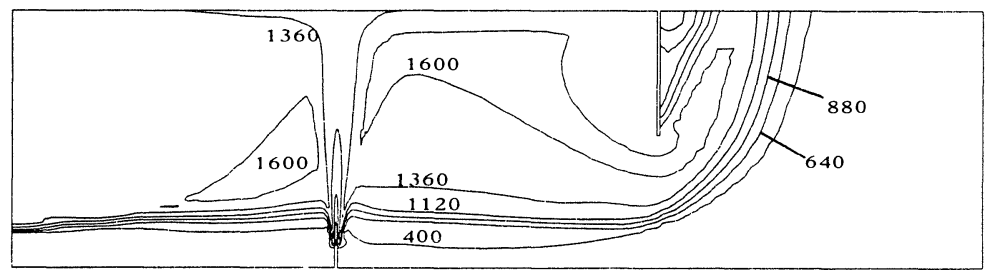

Figure 3 Predicted temperature contours at central section with simplified treatment for radiative heat loss $(\mathrm{K})$.

From the temperature distribution in Figure 2, we can also see a very thin interfacing layer between the upper hot and the lower cold zones. This interfacing layer is also explicitly plotted in Figure 4 for the central section. Within this thin layer, the temperature gradient is very high - increasing from about $400 \mathrm{~K}$ to $1200 \mathrm{~K}$ in $0.3 \mathrm{~m}$. This characteristic of compartment fires implies that the mixing process between the upper hot zone and the lower cold zone is very limited, which is commonly known as the basis of the two-zone fire model. It should be noted that in the region above the jet $(4.9 \mathrm{~m}$ to the vent), the interface is very thick. This is attributed to the high velocity of the fuel jet $(150 \mathrm{~m} / \mathrm{s})$. The surface of the bottom of this interfacing layer is plotted in Figure 5. It is seen that this surface is almost a plane except in the region of the jet. 


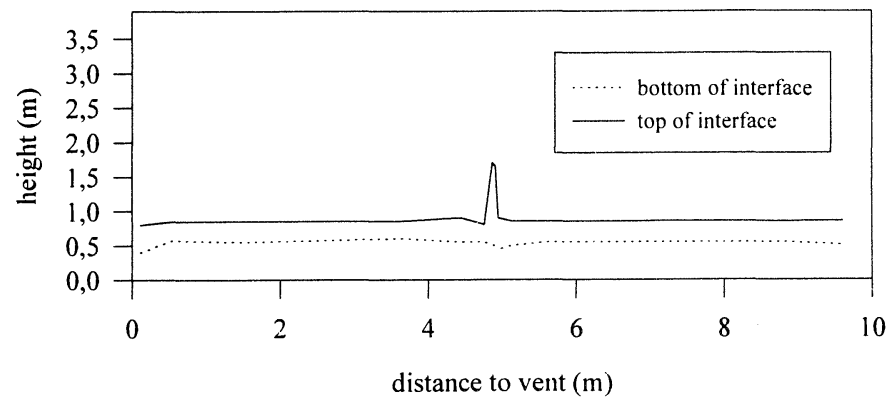

Figure 4 Predicted interface position between upper hot and lower cold zones at central section.

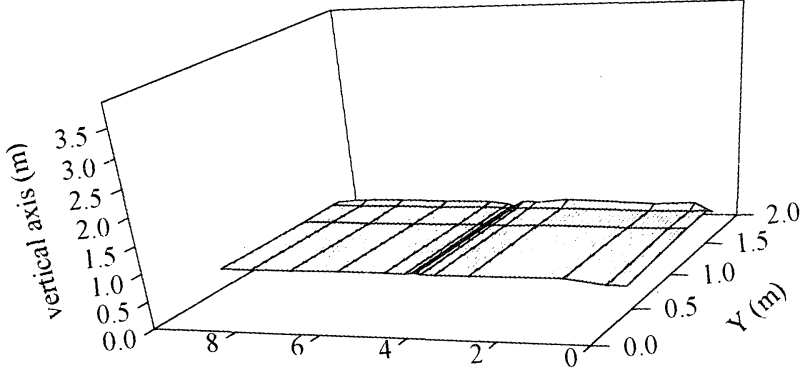

distance to vent $(\mathrm{m})$

Figure 5 Predicted lower surface position of the interface.

Predicted and measured values for the temperature distributions in the three vertical lines are shown in Figure 6. It is seen that the model predicted the correct trend in both the AB line and the $\mathrm{CD}$ line. Quantitatively, the model seems to over-predict the temperatures in the upper part of the compartment and under-predict the temperatures in the lower part. The maximum discrepancies in the upper parts are around $20 \%$. The largest discrepancies are found between the predicted and measured values in the lower part of the vent. Other investigators $[6,22]$ have also reported similar trends. The vent is the most sensitive location for both the numerical model and experimental measurements. Due to heat losses to the compartment wall and the cold air, the temperatures of the vented gas are expected to be generally lower than the hottest region within the compartment. This is reflected in both the measured and predicted values. The predicted results also show a slightly hotter stream in the middle of the vented gas, which is expected, as more heat is lost to the compartment wall above this stream. This hot stream is not shown in the measured data for the particular test case used. However, it is present in the measured data for some other test cases within the same series of compartment jet fire test program [2]. 


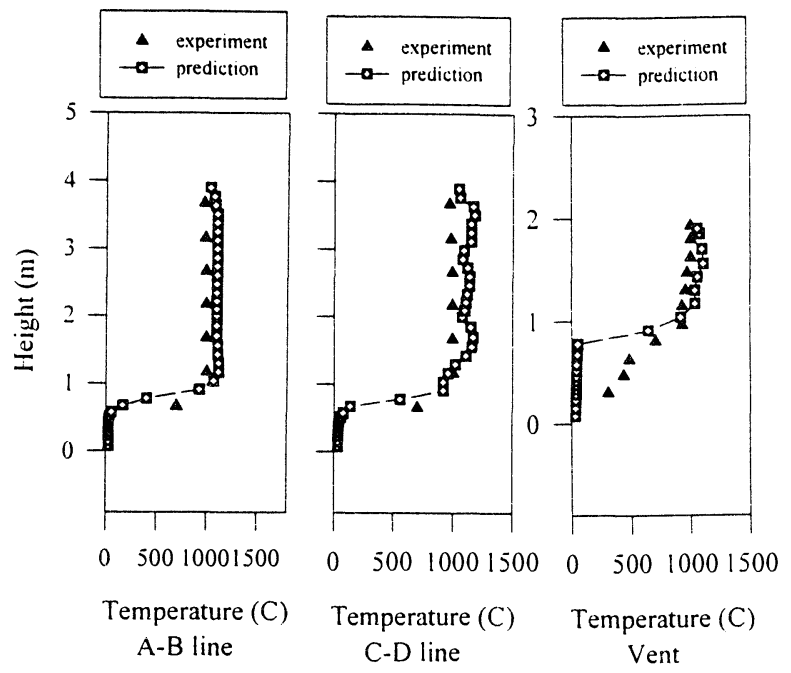

Figure 6 Comparison between predicted and measured temperature distributions.

As mentioned above, for all the three vertical lines, the predicted temperatures in the lower cold layer are lower than the experimental results with the largest discrepancy occurring at the vent. This may also be partially due to the uncertainties, which are inherent in the thermocouple readings. Some recent compartment fire experiments by Blevin [23] have shown that most extreme errors occur in the lower part, when the gas temperature is low and the surrounding temperature is high since radiation heat losses or gains on thermocouples are often not considered during experiment. On the other hand, Blevin indicated that the most likely error in the upper layer normally leads to the actual temperatures being higher than the measured values. This can partly explain the discrepancy. Another reason for the upper layer discrepancy may be rooted to the use of the Constrained Equilibrium method, which is based on the equilibrium assumption.

Figure 7 gives the predicted result of soot distribution. It shows a high soot concentration areas near the left wall and the vent. In both areas, the mixture fractions are larger than the stoichiometric value; i.e. they are fuel rich. Unfortunately, only one point at the vent (point $\mathrm{E}$ in Figure 1) was measured for soot concentration in the experiment. The measured soot concentration at point $\mathrm{E}$ is $0.5 \mathrm{~g} / \mathrm{m}^{3}$. This is in excellent agreement with the predicted value, which is $0.55 \mathrm{~g} / \mathrm{m}^{3}$. However, from this single point comparison, it is difficult to draw any specific conclusion about the accuracy of the current soot prediction. More detailed experimental measurements are required for any meaningful comparison.

The predicted $\mathrm{CO}$ distribution is given in Figure 8. More $\mathrm{CO}$ is found to have formed in the fuel rich region since there is not enough oxygen for its oxidation into $\mathrm{CO}_{2}$. Again, only one point at the vent (point $\mathrm{E}$ ) was measured for $\mathrm{CO}$ concentration. The measured value for $\mathrm{CO}$ concentration at point $\mathrm{E}$ is 0.04 in comparison with the predicted value of 0.072 . Previous 
research has also shown that the equilibrium method can substantially over-predict $\mathrm{CO}$ concentrations [24]. The predicted $\mathrm{CO}_{2}$ contours are given in Figure 9. Unlike the distribution of $\mathrm{CO}, \mathrm{CO}_{2}$ distribution shows that more $\mathrm{CO}_{2}$ is formed in the region where the air and fuel is mixed at almost the stoichiometric ratio. Less $\mathrm{CO}_{2}$ is formed in the fuel rich. The measured value at point $\mathrm{E}$ is about 0.1 , which is in reasonable agreement with the predicted value of 0.08 . But again, it is difficult to draw any specific conclusion from this single point comparison. For the $\mathrm{OH}$ distribution, as shown in Figure 10, it is clearly seen that more $\mathrm{OH}$ is formed in the high temperature region. In the fuel-rich region, where $\mathrm{CO}$ and soot concentrations are high, less $\mathrm{OH}$ is found. This finding is consistent with the experimental results of Kennedy et al. in [25].

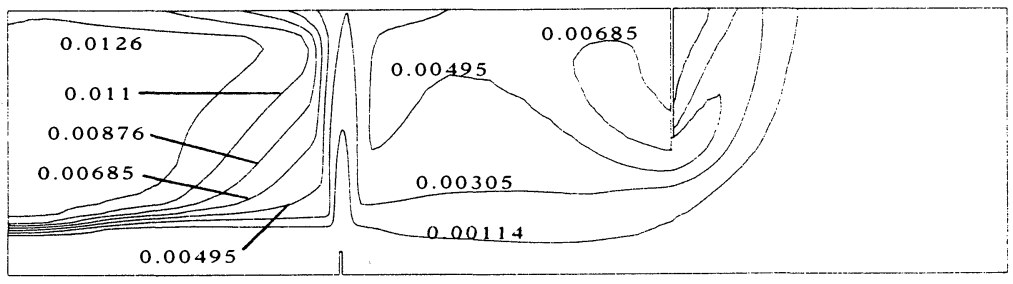

Figure 7 Predicted soot mass fraction at central section.

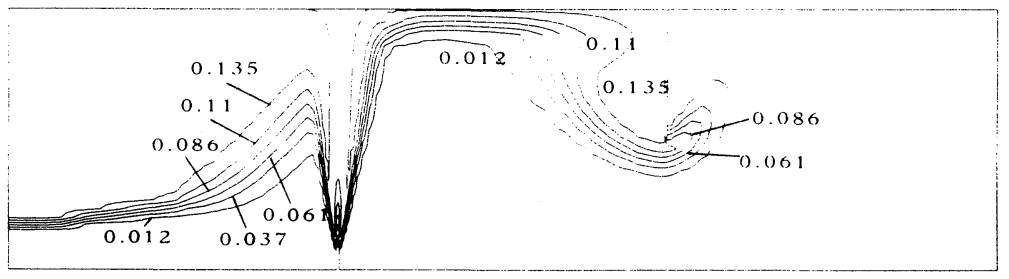

Figure 8 Predicted mole fraction at central section.

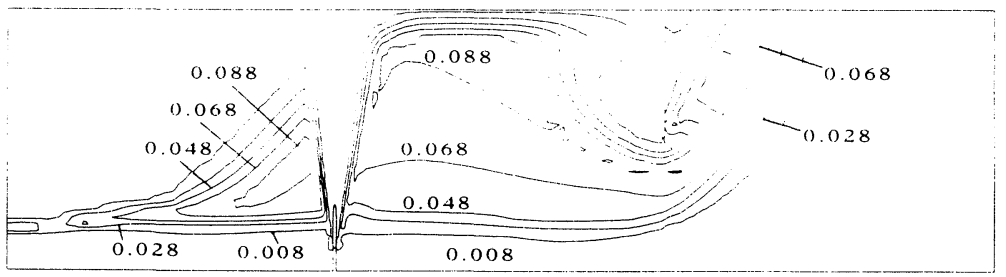

Figure 9 Predicted $\mathrm{CO}_{2}$ mole fraction at central section.

The comparison between the predicted and measured velocities at the vent is presented in Figure 11. In the upper part of the vent, excellent agreement is found. But relatively big error exists in the lower part. This is probably due to the fact that the $k-\varepsilon$ model used in the study 
can not capture the full details of the complicated flow process in the compartment in which highly 3-D recirculation regions exist. Although there are some differences between the predicted and measured temperatures as discussed above, the model has predicted the correct trend of the velocity distribution.

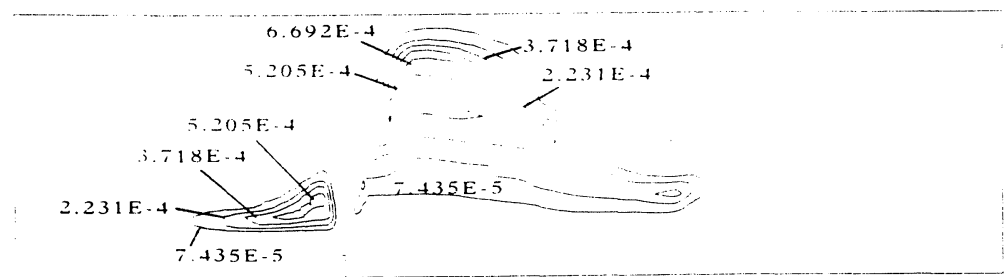

Figure 10 Predicted $\mathrm{OH}$ mole fraction at central section.

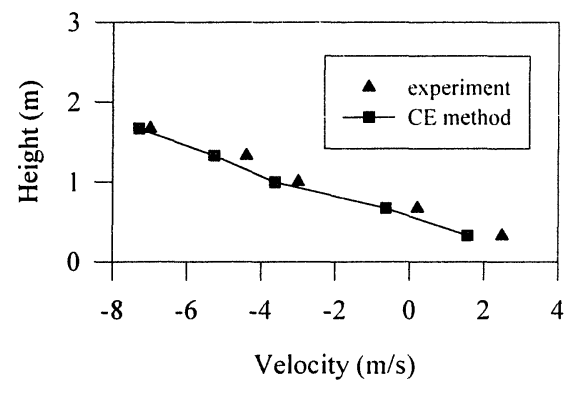

Figure 11 Comparison between measured and predicted axial velocity at vent.
The predicted and measured total incident heat fluxes at the roof are given in Figure 12. The comparison between the experimental data and the predicted results indicates that the models can predict the heat flux correctly. The highest heat flux point appears around the stagnation point. Although the radiative heat transfer at this point is lower because of the cold jet, the convective heat transfer is high in the impinging region.

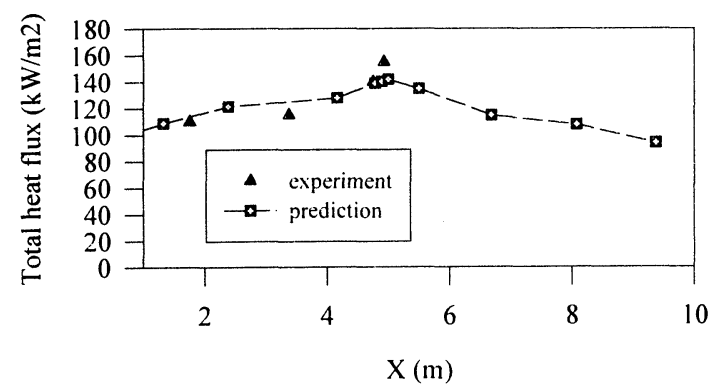

Figure 12 Comparison between predicted and measured total heat flux on the roof.

\section{CONCLUSIONS}

The constrained equilibrium method has been used to couple the calculation of combustion 
and radiative heat exchange. The current model can predict the detailed distributions of velocity, toxic combustion products and the concentration of gaseous species. Predictions have been made for a large-scale compartment jet fire where published full-scale testing data is available. At the upper part of the vent, excellent agreement has been achieved between the predicted and measured velocity. Relatively large discrepancies exist at the lower part. These discrepancies are thought to be partially caused by the use of the k- $\varepsilon$ model that is known to have difficulties with anisotropic flows. For the two vertical lines within the compartment where experimental data is available, the predicted temperature values are in reasonable agreement with the measured results. The predicted temperature distributions at the vent are also in reasonable agreement with experimental data.

Only one single point at the vent was measured for soot, $\mathrm{CO}$ and $\mathrm{CO}_{2}$ concentrations. The predictions for soot and $\mathrm{CO}_{2}$ are in good agreement with the experimental data while the model over-predicted the $\mathrm{CO}$ concentration at that point. However, it will not be convincing for us to draw any conclusion from this single point comparison. In this sense, more detailed measurements will be beneficial for the validation of the current and other computational fire models. The current study has also shown that radiative heat transfer plays an important role in the development of compartment fires. It is also noticed that soot is formed in the upper part of the compartment, mainly near the two side walls where the mixture is fuel rich due to the lack of mixing with the incoming fresh air. The predicted $\mathrm{CO}$ distribution shows a similar trend. The prediction has also revealed a thin interfacing layer between the upper hot region and the lower cold region in which the temperature gradient is very high. Convection in the impinging region is very strong. Modifications to the local convective heat transfer coefficients in the impinging region, which are based on some established correlations, are found to have further improved the predictions for the wall heat fluxes.

\section{Acknowledgement}

The present work is funded by the Engineering and Physical Science Research Council (EPSRC) in the UK under Grant GR/K26523. The authors would also like to acknowledge Dr Mike Fairweather of Leeds University and Dr Andy Johnson of Shell Research Limited for their support. The Steel Construction Institute is acknowledged for supplying the experimental data.

\section{REFERENCES}

1. Large scale compartment fires: experimental details and data obtained in test comp-27, Health and Safety Executive, Report-OTO94024, 1995.

2. Chamberlain, A., An Experimental Study of Large-Scale Compartment Jet Fires, Trans I. Chem. E., 72, Part B, 211-219, 1994.

3. Peatross, M. J. and Beyler, C. L., Ventilation effects on compartment fire characterisation, Fire Safety Science-Proceedings of the 5th International Symposium, pp. 403-414, 1997.

4. Fan, W. C. and Wang Z. W., A new numerical calculation method for zone modelling to predict smoke movement in building fires, Fire Safety Science-Proceedings of the 5th International symposium, pp. 487-498, 1997.

5. Hasofer, A. M. and Beck, V. R., A stochastic model for compartment fires, Fire Safety Journal, 28, pp. 207-225, 1997. 
6. Peacock, R. D., Reneke, P. A., Forney, C. L. and Kostreva, M. M., Issues in evaluation of complex fire model, Fire Safety Journal, 30, pp. 103-136, 1998.

7. Jia, F., Galea, E. R. and Patel, M. K., The prediction of fire propagation in enclosure fires, Fire Safety Science-proceedings of the 5th International Symposium, pp. 439-450, 1997.

8. Lewis, M. J., Moss, M. B. and Rubini, P. A., CFD modelling of combustion and heat transfer in compartment fires, Fire Safety Science-proceedings of the 5th International Symposium, pp. 463-474, 1997.

9. Kerrison, L., Galea, E. R. and Patel, M. K., A two-dimensional numerical investigation of the oscillatory flow behaviour in rectangular fire compartments with a single horizontal ceiling vent, Fire Safety Journal, 30, pp. 357-382, 1998.

10. McGrattan, K. B., Baum, H. R. and Rehm, R. G., Large eddy simulation of smoke movement, Fire Safety Journal, 30, pp. 161-178, 1998.

11. Beard, A., Limitations of computer models, Fire Safety Journal, pp. 375-391, 1996.

12. Kwang-tzu Yang, Recent development in field modelling of compartment fires, JSME International Journal, Series B, 37, pp.702-717, 1994.

13. Wen, J. X., Huang, L. Y., Amin, E. M. and Nolen, P., Modelling sooting jet fires in a large scale offshore compartment, 27th Symp. (Int.) on Combustion, The Combustion Institute, 1998.

14. Kennedy, I. M. and Kollmann, W., Predictions of soot in laminar diffusion flames, AIAA Journal, 29, pp. 1452-1457, 1991.

15. Lockwood, F. C. and Shah, N. G., A new radiation solution method for incorporation in general combustion prediction procedures, 18th Symposium (Int.) on Combustion, the Combustion Institute, pp. 1405-1413, 1981.

16 Hubbard, G. L. and Tien, C. L., Infrared mean absorption coefficients of luminous flames and smoke, Journal of heat Transfer, 100, pp. 235-239, 1978.

17. CFX 4.1 Flow Solver User Guide, AEA Technology, October, 1995.

18. Kumar, S., Gupta, A. K. and Cox, G., Effects of thermal radiation on the fluid dynamics of compartment fires, Fire Safety Science-Proceedings of the 5th Int. Symp., pp. 345-354, 1991.

19. Luo, M., He, Y. and Beck, V., Application of field model and two-zone model to flashover fires in a full-scale multi-room single level building, Fire Safety Journal, 29, pp. 1-25, 1997.

20. Leung, K. M., Lindstead, R. P. and Jones, W. P., A simplified reaction mechanism for soot formation in nonpremixed flames, Combustion and Flame, 8791991), pp.289-305.

21. Viskanta, R., Heat transfer to impinging isothermal gas and flame jets, Experimental Thermal and Fluid Science, 6(1993), pp.114-134.

22. Fletcher, D. F. and Kent, J. H., Numerical simulation of smoke movement from a pool fire in a ventilated tunnel, Fire Safety Journal, 239, pp. 305-325, 1994.

23. Blevins, L. G., A new perspective on the thermocouple behaviour in room fires, 27 th Symp. (Int.) on Combustion, The Combustion Institute, 1998.

24. Liew, S.K., Bray, K.N.C. and Moss, J.B., A flamelet model of turbulent non-premixed Combustion, Combust. Sci. Tech., 27(1981), pp.69-73.

25 Kennedy, I. M., Yam, C., Rapp, D. C. and Santoro, R. J., Modelling and measurements of soot and species in a laminar diffusion flame, Combustion and Flame, 107, pp. 368-382, 1996. 